\title{
Yin-yang $\mathrm{v}$ kitajski mitologiji in vprašanje primerjave s slovanskima Belobogom in Černobogom
}

\author{
Maja Milčinski
}

In the paper, the characteristics of Chinese mythology are presented, in particular the absence of the continuous tradition of myth transmission. The correlative tradition of the yinyang forces is taken as the origin of the cosmology of the Xia and Shang dynasties. In the sources of ancient Slavic and Chinese mythologies no evidence of possible analogies between yin-yang and Belobog-Černobog (white-and black-god) has been found. In contrast to the yinyang forces, Belobog-Černobog present two distinctly antagonistic deities.

Ko se danes kulture oz. civilizacije sveta po nujnosti zbližujejo, se sami po sebi pojavljata tudi želja in težnja po njihovem primerjanju. Učinek takih poskusov je lahko tak, da odkrijemo presenetljive podobnosti, lahko pa se tudi izkaže, da obstajata obe primerjani kulturi oz. primerjani sestavini nepovezani in da med njima manjka člen, na katerem bi bilo mogoče graditi primerjavo.

Slovanska Belobog in Černobog ${ }^{1}$ sta po nekaterih lastnostih sicer primerljiva z yinom in yangom, osnovnima načeloma kitajske korelativne dialektike, vendar, kot se je pokazalo $\mathrm{v}$ procesu raziskave prav zaradi njene vpletenosti $\mathrm{v}$ korelativni krog, ki predpostavlja, da eden kot drugi vključujeta v sebi že zametke svojega nasprotja, tudi popolnoma neprimerljiva. ${ }^{2}$ Poleg tega je v slovanskem kontekstu zelo izražen element vrednotenja in enačenja vsega dobrega $\mathrm{z}$ belim načelom in slabega s črnim, kar za kitajsko kulturo nikakor ne bi mogli trditi.

Yin in yang sta na Kitajskem tudi tesno povezana s predstavami o stvarjenju sveta, ki segajo v čas, ko naj še ne bi bilo Neba in Zemlje. To obdobje kaosa, ki mu je vladala ideja

1 Primerjaj: N. Mikhailov, Appunti su *Belobog e *Černobog, v: Ricerche Slavistiche XLI, Roma 1994, str. 41-51; po njem povzemam Helmoldov citat iz Cronicae Slavorum, I, 52 (po C.H. Meyer, Fontes Historiae religionis slavicae, Berolini 1931, str. 44): Est autem Slavorum mirabilis error; nam in conviviis et compotacionibus suis pateram circumferunt, in quam conferunt, non dicam consecracionis, sed execracionis verba sub nomine deorum, boni scilicet atque mali, omnem prosperam fortunam a bono deo, adversam a malo dirigi profitentes. Unde etiam malum deum lingua sua Diabol sive Zcerneboch, id est nigrum deum appellant (...). - Je pa čudna zmota Slovanov; kajti na svojih pojedinah in popivanjih nosijo okoli darilno skledico, na katero naslavljajo ne bom rekel besede posvetitve ampak zaklinjanja pod imenom (dveh) bogov, namreč dobrega in zlega, izpovedujoč (ker verujejo), da vso dobro usodo vodi dobri bog, vso zlo pa slabi (bog). Zato tudi slabega boga v svojem jeziku imenujejo Diabol ali Črnibog to je črnega boga (...).

2 Tudi različni viri - prim. G. Zollinger, Das Yang- und Yin-Prinzip ausserhalb des Chinesischen, A. Francke Verlag, Bern 1949 in V.V. Ivanov, V.N. Toporov, Issledovanija v oblasti slavjanskih drevnostej, Leksičeskie i frazeologičeskie voprosi rekonstrukcii tekstov, Nauka, Moskva 1974 - ne tvegajo primerjav med yinom in yangom in slovanskim Belbogom in Črnbogom. 
Yin-yang v kitajski mitologiji in vprašanje primerjave s slovanskima Belobogom in Černobogom

brez oblike, žalostna, valujoča in prekipevajoče zmedena, je rodilo ločitev dveh načel: yina in yanga. Na Kitajskem torej ni bilo ločitve osebnega Boga od naravnega objekta. Ko naj bi Nebo in Zemlja po ločitvi postala povezana $\mathrm{z}$ načeloma yanga in yina, sta šele začela predstavljati moško in žensko načelo, ki ju združena še nista mogla zastopati.

\section{Uvod}

Kitajska tradicija je bila od začetkov velike azijske civilizacije nekaj tisoč let pr.n.št. dominantna na področju vzhodne Azije. Tako sta imela tudi konfucijanstvo in daoizem velik vpliv v skupnem zgodovinskem razvoju tega področja, ki se je razvilo v celoto pravzaprav zaradi kitajske vizije sveta. Za kitajsko mitologijo je značilna predvsem odsotnost kontinuirane tradicije prenašanja zgodnjih mitov, kar pripisujejo konfucijanski naravnanosti spreminjanja legend v moralne zgodbe. Te naj bi služile kot vzorec obnašanja prihajajočim rodovom. Dinastija Han (206 pr.n.št.-220 n.št.), po kateri se imenuje tudi najštevilnejši narod na Kitajskem - Hani, je pomembna tudi kot obdobje oblikovanja trajnega pojmovanja zgodovine, politike, vizije časa, kanoniziranja glavnih filozofskih tekstov in klasifikacije različnih filozofov predhanskega obdobja $v$ tako imenovane filozofske šole (jia). To je bil tudi čas oblikovanja klasičnih tekstov v kanonična dela (jing-e), ki so postala osnova ortodoksne vizije vladajoče dinastične avtoritete, s čimer se je vzpostavila tudi zveza med politično močjo in uradnim znanjem, védenjem. ${ }^{3}$

Za obdobje dinastije Shang (pribl.1600-1028 pr.n.št.) so arheologom na voljo bronasti predmeti, najdeni v grobnicah, kot tudi ostanki živali in ljudi, pokopanih v kraljevskih grobnicah. Le-ti naj bi spremljali umrlega $\mathrm{v}$ procesu preobrazbe in prehoda s sveta živih $\mathrm{v}$ svet prednikov. To je bila osnova kulta prednikov, po katerem naj bi bila dobrohotnost duhov prednikov pomembna za dobrobit živih. Izvajanje takšnih slavnostnih ritualov pa je bilo hkrati tudi izvor legitimnosti vladarja in je pomagalo pri vzdrževanju družbene hierarhije. Svetni družbi je vladal vladar, temeljne sile narave in človeške usode pa je nadzoroval Shang Di, najvišje, poglavitno božanstvo, ki je po moči presegalo navadna božanstva in duhove. Shang Di (Zgornje božanstvo, Božanstvo na višinah) je bilo tako visoko, da so se mu zemski vladarji približevali le s posredovanjem duhov svojih prednikov. Za obdobje dinastije Shang je značilna sveta ekologija, harmonija kozmosa, polna svetih sil. Verjeli so namreč, da na svetu poleg ljudi prebivajo tudi različni duhovi in mitske pošasti. Legende, ki so se ob predajanju iz roda $\mathrm{v}$ rod spreminjale, govore o tem, kar bi svojčas utegnila biti bogata mitologija. Izvirala je iz močne povezave človeškega in naravnega sveta ter svetih sil - bogov, božanstev, duhov, sil yina in yanga. To je bila podoba enega in enotnega sveta, brez transcendentnega Boga ali večnega sveta izven tega enotnega kozmosa. Ljudje smo samo del tega, skupaj s svetimi silami in vsem v naravi, s čimer je potrebno vzdrževati harmonijo in ravnotežje. Za kitajsko antiko je tudi značilno, da je razvijala mite o velikih polbožanskih kulturnih junakih in ne o začetkih sveta. Vladarji obdobja dinastije Shang so vzpostavili teokracijo, na čelu katere so bili sami kot sveti vladarji, ki naj bi delovali v dobro vseh s tem, ko so častili prednike, bogove in predvsem najvišje božanstvo Shang Dija. Vse sile vesoljstva - sonce, veter, dež, reke in zemlja - so bila božanstva, ki so jih ljudje častili in jim služili.

3 Prim. A. Cheng, La "Maison des Han": avènement et fin de l'histoire. V: Extrême-Orient - Extrême-Occident 9. Presses Universitaires des Vincennes, 1986, 29. 
Celotnemu panteonu pa je vladalo božanstvo Shang Di, ki naj bi bilo vladarjev neposredni prednik. Hierarhija med vladarjem in njegovimi podaniki se je odražala tudi v hierarhiji najvišjega boga in nižjih božanstev. Takšen vzorec socialnih in tudi božjih rangov, ki je vladal celotnemu redu narave in družbe, je oblikoval središče religiozne tradicije Kitajcev.

\section{Miti o začetkih sveta}

Kitajska tradicija sloni na zgodbah o petih pomembnih modrecih, ki naj bi živeli v tretjem tisočletju pred našim štetjem. Trije suvereni da so udomačevali živali, uvedli družinski red, začeli s poljedeljstvom. Legendarni Rumeni cesar (Huang Di) velja za prednika vseh Kitajcev in simbolnega začetnika kulture, saj njegovemu dvoru pripisujejo iznajdbo pisave, glasbe, zdravilstva, koč, vozov, bronastih ogledal, svile in orožja. Zadnji, peti vladar, pa naj bi ustanovil prvo kitajsko dinastijo Xia (približno 2100-1600 pr.n.št.). Na osnovi dosedanjih arheoloških najdb raziskovalci obstoja te dinastije še niso mogli potrditi, ${ }^{4}$ vendar je jasno, da je bil to pomemben izvor kulture, ki je že poznala pisane simbole. Do danes tudi še ni konkretnih arheoloških dokazov, ki bi v tem času potrjevali verovanje v božanstva hiše in ognjišča, polja in vodnjaka, gora in rek, vendar se raziskovalci ljudske religije nagibajo k tezi, da so bila ta božanstva vendarle že v tem času središče religijske prakse Kitajcev. ${ }^{5}$

V najstarejših kitajskih besedilih zaman iščemo mite o stvarjenju, izvoru zemlje in ljudi. Dokaj pozno ${ }^{6}$ se v literaturi pojavi lik Stvarnika, Pan Guja, ki naj bi bil ločil Zemljo od Neba. Pred eoni da sta bila Zemlja in Nebo združena v veliko jajce, v katerem je prebival Pan $\mathrm{Gu}$ in počasi rasel, vse dokler ni postal velikan, visok 90.000 milj. Spal je 18.000 let, nekega dne pa se je prebudil, odprl oči in opazil vse naokrog temo. Pograbil je sekiro in razbil jajce na dvoje. Lažji del se je dvignil in postal Nebo, težji pa se je spustil in postal Zemlja. Ker se je Pan Gu bal, da bi se Zemlja in Nebo ponovno združila, ju je kot steber držal narazen in čez desettisoč let je bilo Nebo že tako daleč, da bi bila ponovna združitev z Zemljo nemogoča. Utrujen je Pan Gu omahnil na tla in umrl. Iz njegovega levega očesa je nastalo sonce, iz desnega pa luna. Iz telesa so nastala gorovja, iz krvi reke in iz las drevesa in rože. Iz kosti so nastale kovine in trdo skalovje in iz njegovega znoja dež in rosa. ${ }^{7} \mathrm{~V}$ nadaljevanju tega mita naj bi bila nekega dne prišla na svet boginja $\mathrm{Nu}$ Wa. Potovala je po gorah in rekah sveta, ki ga je ustvaril Pan Gu in ugotovila, da bi ga bilo treba z nečim oživiti. Ko je bila utrujena, je sedla ob jezero, kjer je v odsevu vode opazila lastno podobo. Domislila si je, da bi bilo lepo ustvariti nekaj podobnega njej sami in tako je pričela iz vode in blata oblikovati lutko, ki je oživela tisti trenutek, ko jo je postavila na tla. Lahko je hodila, skakala in govorila in $\mathrm{Nu}$ Wa jo je imenovala “človeško bitje.” Po prvi figuri jih je oblikovala še veliko in vse so oživele. Ker pa je bilo to zelo zamudno, je pomočila vejo iz trstja v blato in iz vsake kapljice blata, ki je padla na tla, je nastalo novo človeško bitje. Čez čas je razdelila ljudi na moške in ženske, ki so s potomci oživili svet. ${ }^{8}$

\footnotetext{
${ }^{4}$ Najnovejše najdbe, ki pričajo o enem najstarejših civilizacijskih centrov Azije prav na Kitajskem, utegnejo to spremeniti.

5 Prim. C. Schirokauer, A Brief History of Chinese Civilization. Harcourt Brace Jovanovich. New York, $1991,17$.

6 Nekateri avtorji postavljajo prve omembe mita v 6. stoletje n.št. Prim. E. Erkes, Eine P'an-ku-Mythe der HsiaZeit? In: E. Erkes, Spuren chinesischer Weltschöpfungsmythen. T'oung-pao XXXVIII (1931), 367.

7 Chinese Myths. Guoji shudian, Beijing, 1986.

8 Ibid., 5.
} 
Yin-yang v kitajski mitologiji in vprašanje primerjave s slovanskima Belobogom in Černobogom

\section{Sile yina in yanga. Dao.}

Nikakor ni mogoče trditi, da sta pranačeli yin in yang identični s staroslovanskima Belobog-Černobog. Vendar dvojici nastopata v večini starih civilizacij. Posebnost kitajske je $\mathrm{v}$ tem, da je $\mathrm{z}$ njima zgradila korelativistično dialektiko, ki nekaterim avtorjem pomeni največji prispevek kitajske civilizacije človeštvu. ${ }^{9}$ Za razliko od judovsko-krščanske tradicije, $\mathrm{v}$ kateri je človek oblikovan po božji podobi in je zaradi svojega posebnega mesta v naravi tudi obsojen na življenje, ločeno od narave, je šlo Kitajcem predvsem za vzpostavljanje harmonije $\mathrm{z}$ naravo in silami $\mathrm{v}$ njej. $\mathrm{V}$ izteku grške filozofske tradicije je človek razuma postavljen $\mathrm{v}$ nasprotje $\mathrm{z}$ naravo, $\mathrm{s}$ čimer je bil zarisan neizogiben konflikt med človeško racionalnostjo in kozmično naravo. Filozofija yina in yanga, ki jo povzameta in modificirata Yijing in daoizem, pa si prizadeva ponovno vzpostaviti človekovo povezanost s celotnim kozmosom. To opisujejo kot vrnitev domov, vrnitev k materi, povratek v maternico, pomeni pa ponovno vzpostavitev človekove povezanosti z univerzumom. Človekova glavna naloga je vzpostavljanje harmonije s kozmosom, ki pa je v nenehni premeni, z gibanjem, oscilacijo med dvema poloma po vzorcu krožnega vračanja, kot velja to tudi za ritem letnih časov. Zgodnje daoistične kozmološke teorije so bile osnova kasnejši daoistični alkimiji kontemplacije in interiorizacije, proizvajanja čistih esenc in sestavin, ki naj bi vodile do ustvarjanja božanskega embrija oziroma "notranjega telesa" alkimističnega adepta. Osnova različnim tehnikam je nauk o povratku k prvotni naravi. Pojem "povratka” je povezan z ohranjanjem Daa kot prvotne in nediferencirane enosti pred delitvijo na yin in yang in na "desettisoč stvari," ki pomenijo pač vse kar obstaja.

Gibanje Daa je krožno vračanje; vedenje Daa je šibkost.

Iz bivajočega so vzniknile vse stvari sveta, a bivajoče je izšlo iz nebivajočega. ${ }^{10}$

Nenehna menjava kozmičnih sil yina in yanga je Dao.

Dao je rodil Eno,

Eno je rodilo dvoje,

dvoje je rodilo troje,

in troje je rodilo desettisoč bitij.

Desettisoč bitij nosi yin, objame yang

in združi vseobsežne sile dah. ${ }^{11}$

Dao pa ni personaliziran princip, ampak je popolnoma spontano načelo.

Nekaj je, prej kot Nebo in Zemlja,

iz kaosa nastalo;

9 J. Needham, Science and Civilisation in China. Cambridge University Press, 1980.

${ }^{10}$ Dao de jing 40. V: Klasiki daoizma. Slovenska matica, Ljubljana, 1992, 112.

${ }^{11}$ Dao de jing 42. Ibid., 115. 
samotno tiho, neskončno širno,

$v$ sebi samem nespremenjeno,

v kroženju neizčrpno:

pramati vesoljstva lahko bi mu rekli.

Njegovega imena ne poznam.

Nerad ga imenujem Dao,

in če naj ga označim,

mu rečem "Veliki",

veliki - ker izgineva,

izgineva - je torej daleč,

daleč - vendar se vrača.

Torej je velik Dao,

veliko je Nebo,

velika je Zemlja

in velik je tudi človek.

Človek si za vzor jemlje Zemljo;

Zemlja si za vzor jemlje Nebo;

nebo si za vzor jemlje Dao;

in Dao si za vzor jemlje tisto, kar je

takšno samo po sebi. ${ }^{12}$

Dao je torej tista realnost, ki resnično obstaja iz lastne sile, edina, ki v svoji eksistenci ni odvisna od česa drugega.

Zhuang Zi, drugi pomembni daoistični filozof, zgoraj navedene Lao Zijeve misli razvije takole:

Zatorej, Eno je tisto, kar ljubite, česar ne ljubite, je pa prav tako tisto Eno. Tisto, s čimer se čutite eno, je Eno, tisto, s čimer se ne čutite eno, pa je tudi Eno. V tem, kar je njihovo Eno, so tovariši ljudi. Pravi človek je pa tisti, pri katerem sta Nebo in Človek v ravnotežju.

Smrt in življenje sta usoda. To, da je večna, kot je neprekinjena menjava dneva in noči, je utemeljeno v Nebu. Da obstajajo za človeka meje, ki jih ni mogoče prekoračiti, temelji na splošnih razmerah, v katerih žive bitja. Ljudje zrejo v Nebu svojega očeta in ga osebno ljubijo. Koliko bolj moramo ljubiti to, kar je višje od Neba! Ljudje vidijo v knezu nekoga, ki je boljši od njih in so pripravljeni zanj umreti. Koliko bolj moramo ravnati tako $v$ odnosu do plemenitnika! ${ }^{13}$

\section{Krepost pa opisuje kot:}

Na prazačetku je bilo Ne-bivanje. Bilo je nepoimenljivo. Iz tega se je dvignilo Eno. To Eno - vendar v svojem bivanju še brez oblike, kakršno morajo dobiti stvari, da se morejo roditi - se imenuje krepost. Ker še nima oblike, pa - čeprav so v njem že nasnovani deli, pa le ne razodeva še nobenih locitev - se imenuje pojem. Ker v svojem vztrajanju in gibanju ustvarja stvari in $v$ končanih stvareh ustvarja svoj imanentni zakon, se imenuje oblika. Telesna oblika, učinkovanje, se imenuje narava. Če se narava goji, se vrne nazaj h kreposti. Ta krepost pa se v svoji najvišji

${ }^{12}$ Dao de jing 25. Ibid., 88.

${ }^{13}$ Klasiki daoizma. Slovenska matica, Ljubljana, 1992, 219. 
Yin-yang v kitajski mitologiji in vprašanje primerjave s slovanskima Belobogom in Černobogom

stopnji ujema s tistim "prazačetim". V tem ujemanju se pokaže kot onostransko. V svoji onostranskosti se izkaže kot veliko. Od zunanjega sveta se ogradi. Ko se to zgodi, postane eno s silami Neba in Zemlje. Ta združitev je prikrita. Videti je kot norost, kot nezavestnost. To je temna, skrita krepost. Grobo, nezavestno, udeleženi ste v Veliki podreditvi. ${ }^{14}$

Ko opisujemo kitajska pojmovanja o nastanku, razvoju in delovanju sveta, se moramo zavedati, da ostajamo samo na aproksimativni ravni. V kitajski kulturi namreč ni razlikovanja med materijo in duhom, kot je postalo le-to splošno sprejeto v Evropi. Kitajci tudi nikdar niso imeli predstave o docela transcendentnem Bogu, ločenem od univerzuma, svoje stvaritve. Kitajski univerzum ne sestoji iz materije in duha, temveč je to kontinuum mnogih različnih stanj ene same snovi, energetske konstelacije, imenovane qi. V tem univerzumu tudi človek ne obstaja iz materialnega telesa in duha, duše, temveč iz množice bolj ali manj subtilnih qijev. Kot pravi Zhuang Zi:

Življenje je spremljevalec smrti, smrt je začetek življenja. Kdo razume njuno delovanje? Človekovo življenje je sestavljanje diha. Če se sestavi, potem je to življenje, če pa se razsuje, je to smrt. Če pa sta si smrt in življenje družabnika, česa se imam potem še bati? ${ }^{15}$

Yin in yang sta tudi osnovni načeli Knjige premen (Yijing) in sta tudi podlaga oblikovanju neokonfucijanskega diagrama Velikega poslednjega (Taiji du). V gibanju se $\mathrm{v}$ Velikem poslednjem manifestira njegov yang aspekt, ko pa mirovanje doseže mejo, se ponovno sprevrže v gibanje. Tako gibanje in mirovanje izmenoma nastopita kot izvor drug drugega. $\mathrm{S}$ premeno yina in yanga pa nastaja pet energetskih stanj - voda, ogenj, les, kovina in zemlja. Yin in yang torej $\mathrm{z}$ medsebojnim učinkovanjem ustvarjata nešteto stvari, ki se spet reproducirajo. Tako se njihova transformacija in premena nadaljujeta $\mathrm{v}$ nedogled.

\section{Sklep}

Mitologiji Kitajcev lahko sledimo od številnih mitskih bitij - ki skrivnostno prežemajo svet narave in ljudi in imajo v ljudski zavesti vsakovrstne funkcije človeku v prid ali v oviro in škodo -, preko višjih božanskih bitij in najvišjega (Shang Di) med njimi, ter na koncu na ravni neizgovorljivega, $\mathrm{z}$ besedami izrečeno in zapisano neizrazljivega. To je grafično upodobljeno v prikazu kozmološkega procesa $\mathrm{z}$ diagramom Taiji du, v katerem so zgoščene filozofije Yijinga, yina in yanga, daoizma, ki so stoletja rastle vzporedno in deloma tudi druga iz druge.

Težko bi primerjali to dolgo, plodno tradicijo Kitajcev z obdobjem nastajajoče civilizacije Slovanov. Ob pokristjanjevanju naj bi se sicer ohranili stari obredi, zagovori, šege in zaklinjanja, bajke in ponekod čaščenje dreves in studencev. Kot residua magičnega mišljenja bi takšna stara verovanja in šege našli še marsikje po svetu. Zaman bi bilo iskati hierarhijo v mnoštvu fantastičnih bitij, vragov, vražičev, vampirjev in škratov, še dlje pa je odmaknjeno upanje na odkritje neke svojske arhaične kozmogonije in prek te izdelane življenjske filozofije, kot so jo izoblikovali in ohranili Kitajci.

Raziskovalci ${ }^{16}$ so pričakovali, da se jim utegne v dvojici Belobog-Černobog odkriti pomembna simbolika v smislu razmerja dobro:zlo in drugih podobnih objemajočih se

\footnotetext{
${ }^{14}$ Ibid., 262-263.

${ }^{15}$ Ibid., 348-349.

${ }^{16}$ Med njimi Nikolai Mikhailov, n. d.
} 
nasprotkov. ${ }^{17}$ To pa se ni zgodilo. O dvojnosti npr. "Deus bonus": "Deus malus" tu ne moremo govoriti. Rekonstruirana oblika "Belobog" utegne biti atributivni naziv za Sventovita, registrirana oblika "Černobog" pa eden od nazivov nekega "negativnega božanstva."

${ }^{17}$ Tako, kot je kitajska filozofija ustvarila pomembno korelativnost med yinom in yangom. 
Yin-yang v kitajski mitologiji in vprašanje primerjave s slovanskima Belobogom in Černobogom

\section{Yin-yang in Chinese Mythology as Compared to the Slavic Belobog and Černobog}

Maja Milčinski

In the paper, the characteristics of Chinese mythology are presented, in particular the absence of the continuous tradition of myth transmission. The myth of the legendary Pan $\mathrm{Gu}$ is dealt with. The correlative tradition of the yin-yang forces is taken as the origin of the cosmology of the Xia and Shang dynasties. In the sources of ancient Slavic and Chinese mythologies no evidence of possible analogies between yin-yang and Belobog-Černobog (white- and black-god) has been found. In contrast to the yin-yang forces, Belobog-Černobog present two distinctly antagonistic deities. The relation between yin and yang, which has been illuminated by the texts of daoist philosophers, and Yijing, is correlative, as both of the elements are equally valued. 